\title{
Análise da interação universidade-empresa para o desenvolvimento inovativo a partir da perspectiva teórica institucionalista-evolucionária
}

\author{
Dannyela da Cunha Lemos* \\ Silvio Antonio Ferraz Cario ${ }^{* *}$
}

Recebido: 09/06/2014 Versão Revisada (entregue): 19/10/2014 Aprovado: 29/10/2014

\begin{abstract}
RESUMO
O presente artigo tem como objetivo analisar a interação universidade-empresa (U-E) para o desenvolvimento inovativo em Santa Catarina, por meio da perspectiva teórica institucionalistaevolucionária. Trata-se de um estudo descritivo-explicativo de abordagem qualitativa, a partir de pesquisa de campo nas quatro maiores universidades de Santa Catarina. Para a coleta de dados foram realizadas 38 entrevistas em profundidade. Os dados foram tratados por meio da análise de conteúdo categorial, com o apoio do software de análise de dados qualitativos Atlas/ti, segundo as categorias de análise dimensão individual (hábitos), dimensão coletiva (instituiçōes), tecnologias físicas e tecnologias sociais. Os resultados apontaram que a interação U-E em Santa Catarina encontra-se bastante condicionada à dimensão individual, de maneira que a aproximação com o setor produtivo e o estabelecimento de parcerias não se configuram de fato como uma estratégia institucional, mas refletem ações isoladas de pesquisadores, grupos de pesquisa ou departamentos.
\end{abstract}

PALAVRAS-CHAVE | Interação Universidade-Empresa; Perspectiva Institucionalista-Evolucionária; Hábitos; Instituiçôes; Tecnologia Física; Tecnologia Social

CÓdigo JEL | O; O30

* Universidade do Estado de Santa Catarina (Udesc), Florianópolis (SC), Brasil. E-mail: lemosda@gmail.com.

** Universidade Federal de Santa Catarina (UFSC), Florianópolis (SC), Brasil. E-mail: fecario@yahoo.com.br. 


\title{
Analysis of the university-industry interaction for innovative development from the evolutionary-institutional theoretical perspective
}

\begin{abstract}
This article aims to analyze the university-industry (U-I) interaction to the innovative development, in Santa Catarina, through the evolutionary-institutional theoretical perspective. It was a descriptive-explanatory study with a qualitative approach and conducted through field research, in the four major universities of Santa Catarina. For data collection, it was possible to perform 38 interviews in depth. The data was treated by analysis of categorical content, with the support of the qualitative data analysis software Atlas/ti, from the following categories of analysis: individual dimension (habits), collective dimension (institutions), physical technologies and social technologies. The results showed that the U-I interaction, in Santa Catarina, is highly conditioned to the individual dimension. Thus, the approach to the productive sector and partnerships does not qualify, indeed, as an institutional strategy. However, it reflects isolated actions of researchers, research groups or departments.
\end{abstract}

KEYWORDS | University-Industry Interaction; Evolutionary-Institutional Perspective; Habits; Institutions; Physical Technology; Social Technology

JEL-CODE | O; O30 


\section{Introdução}

O processo inovativo é fruto da coletividade, envolvendo, portanto, múltiplos atores e desenvolvendo-se a partir das interações estabelecidas entre estes (EDQUIST, 2007). Além disso, trata-se também de um processo sistemático e não decorrente do acaso, que precisa ser institucionalizado do ponto de vista tanto das organizações como das regiōes, setores e países. Reconhecendo as ligações entre as instituições e a inovação, pode-se identificar uma "perspectiva institucionalista-evolucionária" que busca a compreensão de padrões de ação em termos de comportamentos, ao longo do tempo, dos quais derivam processos de aprendizado individual e coletivo.

Dentro dessa perspectiva, pode-se destacar a importância do Sistema Nacional de Inovação (SNI) e, particularmente, as interações que ocorrem entre o meio acadêmico e o empresarial, reforçando-se o papel de dois atores: as empresas e as universidades. Assim, cria-se um novo padrão de relacionamento entre o mundo acadêmico e o empresarial, em que as universidades assumem um papel determinante no desenvolvimento do conhecimento como suporte à inovação.

O estudo da interação universidade-empresa (U-E), particularmente no Brasil, cuja trajetória do SNI ainda é recente e em fase de construção e consolidação, abre amplo campo para discussão e pesquisa, permitindo a realização de estudos em diferentes dimensões, ao focalizar as interações U-E seja no SNI brasileiro como um todo, seja com recortes regionais. Nessa direção, o presente trabalho tem a intenção de promover um aprofundamento e ampliação do conhecimento na temática da interação U-E, utilizando o aporte teórico dos sistemas de inovação, referencial já consagrado neste campo, mas também dialogando com a perspectiva institucional.

Este artigo focaliza o recorte regional abrangendo o Estado de Santa Catarina e particularmente o seu Sistema de Ensino Superior. A escolha do estado para o estudo do fenômeno apoia-se nos dados apresentados nos Censos do Diretório dos Grupos de Pesquisa do CNPq, realizados de 2002 a 2010. Verifica-se que tem crescido o número não só de grupos de pesquisa no estado, na ordem de 59,67\%, mas também de grupos de pesquisa que se relacionam com o setor produtivo, em 141,41\%. Santa Catarina ocupa a sétima posição no total de grupos de pesquisa e, dos 1.263 grupos registrados no estado, $18,92 \%$ relacionam-se com o setor produtivo. Esse valor está acima da média nacional, que gira em torno de $12,74 \%$ e também representa o maior percentual entre todos os estados brasileiros (CNPq, s/d).

$\mathrm{O}$ artigo está organizado em cinco seções, incluindo essa introdução. A seguir, é apresentada uma revisão teórica que relaciona alguns aspectos da interação U-E 
na perspectiva institucionalista-evolucionária tratada nas categorias de análise dos resultados da pesquisa. Posteriormente são descritos os procedimentos metodológicos e expostos os resultados da pesquisa, organizados por categoria de análise: dimensão individual (hábitos); dimensão coletiva (instituições); tecnologias físicas; e tecnologias sociais. Por fim, são tecidas as considerações finais.

\section{A interação universidade-empresa na perspectiva teórica institucionalista-evolucionária}

O Sistema Nacional de Inovação (SNI) compreende um arranjo institucional envolvendo múltiplos participantes, tais como: empresas e suas redes de cooperação e interação; universidades e institutos de pesquisa; instituições de ensino; sistema financeiro; leis; mecanismos mercantis e não-mercantis de seleção; governos; e mecanismos e instituições de coordenação. Tal arranjo articula riqueza econômica com competências tecnológicas fundamentais, motivo pelo qual ganham relevância as instituições e os mecanismos de cooperação (BERNARDES; ALBUQUERQUE, 2003; FERNANDES et al., 2010).

A literatura relativa ao SNI enfatiza a importância das interaçôes e dos arranjos institucionais e, nesse sentido considera as universidades atores que podem contribuir para o desenvolvimento econômico, num contexto de uma economia baseada no conhecimento. No SNI as universidades podem estabelecer ligações com a estrutura produtiva que permitam a aceleração da transferência de conhecimento e tecnologia (MOWERY; SAMPAT, 2007).

Nesse contexto, as universidades passam a ser reconhecidas como peças-chave nos sistemas de inovação, por meio de sua participação ativa no processo de produção do conhecimento para inovação. Tal constatação tem levado vários países a implementar políticas que fortaleçam os vínculos entre universidades e empresas, visando um melhor desempenho econômico amparado pela pesquisa acadêmica (MOWERY; SAMPAT, 2007; SAAD; ZAWDIE, 2011; TARTARI; BRESCHI, 2012).

Nesse sentido, dois tipos de políticas se mostram relevantes: aquelas que encorajam a formação de aglomerações regionais econômicas e a formação de spin-offs baseadas na pesquisa acadêmica; e as políticas para estimular as atividades de patenteamento e licenciamento por parte das universidades (PAVITT, 2007; MOWERY; SAMPAT, 2007). Além disso, muitos governos buscam promover a interação U-E por meio da criação de "instituições-ponte" que visam reduzir a lacuna cultural entre as duas partes e facilitar o processo em si (GEUNA; MUSCIO, 2009). No entanto, 
a simples criação de instituições para intensificar a interação U-E, aumentando a participação do número de pesquisadores acadêmicos nas empresas, só faz sentido se promover um engajamento em direção a novos caminhos que ainda não tenham sido trilhados por ambas as partes (BOARDMAN, 2009).

As características mais comuns das interaçóes U-E que emergem da literatura são: a troca de conhecimento como o elemento central da interação U-E (MEYER-KRAMER; SCHMOCH, 1998); a importância dos contatos pessoais e informais, que podem resultar em trocas formais ou mais relações informais (PAVITT, 2007); a complementaridade entre a pesquisa acadêmica e a aplicação industrial, seja pela criação de novos projetos ou pela continuidade de projetos já existentes (COHEN; NELSON; WALSH, 2002; GEUNA; MUSCIO, 2009); e a formação de pessoal para atividades de pesquisa e consultoria em inovação (PAVITT, 2007).

Entre as amplas formas de interação U-E, podem ser identificados os formatos de natureza "colaborativa", em que se incluem a pesquisa colaborativa, a pesquisa contratada e a consultoria, e os formatos de natureza "comercial", englobando o licenciamento/patenteamento, o empreendedorismo acadêmico e a formação de spin-offs (PERKMANN; KING; PAVELIN, 2011). Segundo Lind, Styhre e Aaboen (2013), é possível identificar quatro formas de colaboração distintas que refletem o modo como o trabalho está organizado na interação U-E: forma de colaboração especificada, cujo ator dominante é a empresa e o processo de pesquisa se dá em direção ao produto; forma de colaboração distanciada, cujo ator dominante é a universidade e o processo segue em direção aos resultados da pesquisa; forma de colaboração translacional, em que empresa e universidade conduzem dois processos de pesquisa em paralelo, em direção ao produto e aos resultados da pesquisa; e forma de colaboração desenvolvida, em que empresa e universidade conduzem um processo de pesquisa em direção aos produtos e resultados de pesquisa.

Bekkers e Freitas (2008) apresentam evidências de que a importância dos canais de transferência de conhecimento adotados na interação U-E não estão relacionados propriamente com os setores de atividade, mas sim com as seguintes questões: as características do conhecimento em questão, com seu caráter tácito e sistêmico; a origem disciplinar do conhecimento envolvido; e as características individuais e organizacionais dos envolvidos no processo de transferência de conhecimento (tempo de serviço, publicações, patentes, empreendedorismo e ambiente de pesquisa). Diferentes tipos de processo de transferência de conhecimento exigirão diferentes formas de arranjos interorganizacionais entre a universidade e a empresa. Tais arranjos envolvem a necessidade de troca de informações frequentes, a extensão 
e envolvimento de recursos e regras claras sobre a apropriação do conhecimento produzido (D'ESTE; PATEL, 2007).

Nessa direção, Geuna e Muscio (2009) chamam a atenção para a questão dos modos de governança das interações. A transferência de conhecimento U-E pode ser regida por interaçôes contratuais pessoais entre os pesquisadores das universidades e dasempresas, ou por meio de estruturas formais, tais como departamentos específicos das universidades, escritórios de transferência de tecnologia e outros tipos de organização de transferência de conhecimento.

Como se pode perceber, o elemento institucional é um aspecto marcante no tratamento da interação U-E, uma vez que se revela como uma das características em comum das abordagens relativas ao SNI, em que as instituiçôes figuram como elementos centrais que influenciam a inovação (EDQUIST, 1997).

Nelson e Nelson (2002) argumentam que "a ideia de sistemas de inovação é uma concepção institucional por excelência”. Nesse sentido, os autores sugerem a criação de uma "ponte intelectual" entre as abordagens institucional e evolucionária, uma vez que, segundo sua visão, há uma complementaridade no tratamento da inovação e fortes afinidades naturais que se manifestam na forma de percepções e pressupostos básicos comuns.

A escola neoschumpeteriana vincula, de forma mais precisa, a tecnologia com as instituiçôes, advogando a supremacia do processo de inovação e mudança tecnológica sobre os rumos do crescimento econômico. O enfoque institucionalista, por sua vez, contempla a inclusão dos indivíduos, seus hábitos e idiossincrasias na definição de estratégias institucionalizadas, que originarão o referido processo (CONCEIÇÃO, 2012, p. 109).

Nelson e Nelson (2002) sinalizam que a abordagem dos sistemas de inovação poderia ser ampliada e facilitada se, no âmbito da teoria evolucionária econômica formal, já estivesse incorporada mais da análise institucional. Complementado, Nelson (2008) coloca que existem basicamente dois obstáculos para a construção da ponte intelectual: a falta de clareza em relação ao significado do termo instituição, bem como a diversidade de possibilidades na abordagem do tema; e a forma de tratamento das instituições na literatura acerca de desenvolvimento econômico, que deixa de criar um ponto de apoio com o avanço tecnológico.

Nelson e Sampat (2001) argumentam que, embora o tratamento das instituições possa remeter a uma variedade de coisas em diferentes contextos distintos, é importante olhar para o processo e para a forma como se realiza a atividade econômica, 
tendo como foco aquilo que as instituições fazem. Para tanto, os autores propõem o conceito de tecnologia social. ${ }^{1}$ Em uma atividade ou num aglomerado delas, há um conjunto de procedimentos que precisam ser realizados e requerem insumos específicos e possivelmente algum tipo de equipamento, o que pode ser denominado de "tecnologia física". Contudo, é necessário considerar que tais atividades envolvem também múltiplos atores e exigem, portanto, mecanismos de coordenação e divisão do trabalho, o que se denomina "tecnologia social" (NELSON, 2006, 2008).

Nesta última concepção, o termo tecnologia denota comportamentos cuja intenção é realizar alguma coisa, enquanto o termo social indica que tais comportamentos envolvem ou respondem a ações (reais ou esperadas) de múltiplos agentes. $\mathrm{O}$ conceito de tecnologia social engloba comportamentos associados às coisas que são realizadas dentro de uma organização, bem como aquelas que envolvem diferentes indivíduos ou organizações. De maneira geral, o conceito também pretende incluir os aspectos relacionados aos objetivos que orientam a forma de fazer as coisas, em que o comportamento dos agentes é adaptado para influenciar as ações ou reações dos outros agentes (NELSON, 2006).

Na visão de Conceição (2009, p. 105), o conceito de tecnologia social se revela adequado "porque envolve uma ampla conceituação de atividade econômica, desde sua forma mais padrão, entendida como a forma de se produzir algo, ou, mais genericamente, na produção de algo útil, quanto uma ampla visão que o termo incorpora e sugere". Para Nelson e Sampat (2001, p. 40), "A noção de tecnologias sociais em alguns aspectos é similar às tecnologias físicas, mas envolve a padronização da interação humana em vez de engenharia física”.

Assim como as tecnologias físicas têm requerimentos físicos para sua implementação, tais como maquinaria especializada ou materiais específicos, as tecnologias sociais podem ser institucionalizadas por meio de diferentes formas que sejam aplicadas em contextos específicos para satisfazer diferentes necessidades. Nessa direção, Conceição (2009) coloca que é possível visualizar o sistema de P\&D industrial como um conjunto de atividades relacionadas às tecnologias físicas (procedimentos, laboratórios, centros de pesquisa) e também às tecnologias sociais (divisão do trabalho entre os cientistas e as estruturas de coordenação e direção).

Para Nelson e Nelson (2002, p. 268), as tecnologias sociais representam "aquilo que os estudiosos têm em mente quando eles utilizam o termo instituições”. Segundo

1 É importante destacar que o conceito de tecnologia social (social technology) proposto por Nelson e Sampat (2001) e adotado nesse trabalho difere daquele comumente utilizado no Brasil, em que tecnologia social diz respeito às tecnologias voltadas à inclusão social ou ainda à construção de um estilo alternativo de desenvolvimento. Nesse caso, literalmente o termo seria tecnologia para inclusão social, mas por uma questão de simplificação adotou-se o termo tecnologia social (DAGNINO, 2010). 
os autores, tal concepção se aproxima das definições de instituições amplamente empregadas na literatura corrente, uma vez que "o conceito de tecnologia social é amplo o suficiente para encampar as possíveis formas de organização da atividade dentro de organizações particulares".

De acordo com Nelson (2008, p. 3), "esta concepção de tecnologias sociais e instituições suportando-as parece suficientemente ampla para englobar a maioria dos tipos de coisas tratados como instituições na literatura de sistemas de inovação".

As "tecnologias sociais", institucionalizadas ou não, são fruto de trajetórias idiossincráticas, que condicionam a evolução dos sistemas de inovação. [...] Depreende-se que a importância das "tecnologias sociais institucionalizadas" é fundamental para tratar dos sistemas de inovação, pois essas desempenham importante papel no processo de aprendizado interativo das organizaçôes (e dos indivíduos em seu interior), sobretudo porque a inovação é decorrência da forma como as organizações combinam suas características idiossincráticas com as do meio em que atuam (PEREIRA; DATHEIN, 2012, p. 157-158).

As tecnologias sociais, à medida que se tornam institucionalizadas, criam um suporte para que as tecnologias fisicas evoluam e esta coevolução é fundamental para a consolidação dos sistemas de inovação (PEREIRA; DATHEIN, 2012). Segundo Nelson (2008), é a coevolução das tecnologias fisicas e sociais que permite entender como a inovação impulsiona o crescimento econômico, sendo que a dinâmica da mudança institucional pode ser vista por este foco.

\section{Procedimentos metodológicos}

Trata-se de uma pesquisa descritivo-explicativa de abordagem qualitativa, cujos meios de investigação empregados foram a pesquisa bibliográfica e documental e o levantamento de campo. O universo da pesquisa compreendeu o Sistema de Ensino Superior em Santa Catarina, a partir do qual se definiu uma amostra não probabilística por tipicidade, que adotou como objetos de estudo as quatro maiores universidades de Santa Catarina: Universidade Federal de Santa Catarina (UFSC), Universidade do Estado de Santa Catarina (Udesc), Universidade Regional de Blumenau (Furb) e Universidade do Vale do Itajaí (Univali), considerando a quantidade de grupos de pesquisa interativos e programas de pós-graduação.

A escolha da amostra levou em conta dados provenientes das bases de dados do Inep (2012), do CNPq (2013) e do Capes-Geocapes (2012), que indicaram que as atividades de pós-graduação e pesquisa estão concentradas nas quatro universidades 
tomadas como objeto de estudo. Além disso, tais universidades também pertencem a categorias administrativas diferentes, sendo respectivamente federal, estadual, municipal e privada/comunitária, o que confere maior diversidade de análise.

Para a realização da coleta de dados, elegeram-se, como sujeitos de pesquisa, líderes de grupos de pesquisa que mantêm relacionamento com o setor produtivo, bem como gestores dos núcleos de inovação tecnológica (NITs) das referidas universidades, com os quais foi realizado um total de 38 entrevistas em profundidade. Neste tipo de entrevista o sujeito de pesquisa é convidado a falar livremente sobre um tema, podendo incluir perguntas que buscam dar aprofundamento às reflexões (MINAYO, 2011). Para tanto, foram elaborados dois modelos de roteiro de entrevista com questôes semiestruturadas, sendo um deles destinado à entrevista com o líder do grupo de pesquisa, com 11 questôes, e outro direcionado aos gestores dos NITs, com dez questôes.

Participaram da pesquisa de campo 31 grupos, na figura de seus respectivos líderes, sendo seis grupos das ciências agrárias, um grupo das ciências biológicas, dois das ciências da saúde, cinco das ciências exatas e da terra, quatro das ciências sociais aplicadas e 13 das engenharias. Também foram entrevistados sete gestores dos NITs, envolvendo tanto os atuais como ex-gestores.

Foi empregada a análise de conteúdo categorial, a partir das seguintes categorias de análise: dimensão individual (hábitos); dimensão coletiva (instituições); tecnologias físicas; e tecnologias sociais. Para apoiar a análise e apresentação dos resultados, foi utilizado o software de análise de dados qualitativos Atlas/ti, versão 7.1.3, onde foram gerados os esquemas gráficos (visões de rede) apresentando de maneira ilustrativa as relações entre os dados coletados e sua organização em categorias.

\section{A interação universidade-empresa sob a análise institucionalista- evolucionária}

\subsection{Dimensão individual}

$\mathrm{Na}$ dimensão individual procurou-se caracterizar, dentro do processo de interação U-E e nas distintas situações que ele gera, como se manifestam os comportamentos particulares dos pesquisadores e como se dá a repetição de tais comportamentos criando preferências e disposições.

Os relacionamentos pessoais são extremamente importantes para o estabelecimento dos primeiros contatos com os potenciais parceiros de pesquisa, bem como para que os relacionamentos possam se firmar, conforme expressa esse entrevistado: "Isso acontece [interação U-E] porque eu tenho bons contatos, tenho uma rede de 
relações muito forte, eles [empresas] confiam em mim e eu confio neles" (GP3). As características dos pesquisadores os conduzem a determinados comportamentos, de forma que "o ator e a estrutura institucional, embora diferentes, estão conectados em um círculo de interação e interdependência mútua" (HODGSON, 2011, p. 30).

Assim, o esforço pessoal, em boa parte dos casos, é o fator que determina o sucesso ou insucesso dos relacionamentos com empresas. Nessa direção toma forma a falta de incentivo aos pesquisadores, particularmente o baixo nível de apoio institucional. Justamente uma das funções específicas das instituições em relação às inovaçōes, apontada por Edquist (1997), é prover incentivos que possam gerar um engajamento no processo inovativo, o que, nesse caso, se revela falho, conforme dá conta o seguinte entrevistado: "É uma relação que depende muito do esforço do professor, aí na hora que dá certo ela é institucional” (GP7). Além disso, é preciso estar aberto a outras possibilidades, o que nem sempre se revela tarefa fácil, na visão desse entrevistado: "Eu nunca parei no primeiro não e nem no décimo-terceiro, sou teimoso e convicto de que a gente está fazendo o caminho muito certo, sério, esse modelo já existe há muito tempo em universidades lá fora e dá certo" (GP20).

No caso específico da UFSC, este aspecto foi reforçado pela dificuldade de identificação das competências, por parte do público externo. Segundo entrevistados, tal fato tende a enfatizar ainda mais o aspecto pessoal da relação com empresas, dificultando a institucionalização e, por consequência, sua continuidade. A Furb e Univali já realizaram um trabalho mais estruturado de mapeamento das competências internas e identificação de suas potencialidades junto ao setor produtivo, que é a criação de uma espécie de portfólio de serviços.

O ponto central da dimensão individual é o reconhecimento, por parte dos entrevistados, de que não basta o esforço pessoal e reiteradas ações dos pesquisadores em direção ao estabelecimento de vínculos com o setor produtivo, sendo necessário o respaldo institucional, no sentido de definir o que as pessoas podem e devem ou não fazer, impelindo-as a um comportamento coletivo, que, uma vez institucionalizado, também seja reconhecido. O relato que segue ilustra esse aspecto: "eu acho que essa interação se deu muito sempre do ponto de vista do pesquisador, o pesquisador tem o contato, tem o projeto, não é uma coisa institucional, não é o grupo que faz o contato, [...] é muito do pesquisador que tem interesse e vai atrás e traz para o grupo" (GP31).

A ênfase no aspecto pessoal e não institucional da interação U-E gera riscos para a continuidade da interação U-E, que se manifesta em preocupações perceptíveis junto aos entrevistados. A primeira delas diz respeito ao fato de que, se existe 
dependência por parte da universidade desses comportamentos individuais, isso pode gerar oscilações em termos de apoio aos projetos de parceria, principalmente quando as pessoas ocupam posiçôes estratégicas e possuem poder decisório.

Outra preocupação refere-se à continuidade dos projetos de parceria diante das mudanças no quadro de pesquisadores da universidade, seja por questóes adversas ou motivadas por contingências naturais, tais como a aposentadoria. Conforme coloca Hodgson (2001), a amplitude de vida das instituiçōes é diferente dos indivíduos, o que pode garantir que determinadas posiçóes conquistadas sejam mantidas quando se alcança uma dimensão institucional, que é exatamente o que os entrevistados temem não acontecer, conforme se pode perceber nesse relato: "salvo alguma exceção, então a regra é professores tentando sobreviver, tentando fazer algo de bom [...] a coisa é muito pessoal, isso é a minha lástima, é o [pesquisador x]. [...] se o [pesquisador x] se aposentar ou morrer acabou tudo" (GP3).

Neste contexto, cabe registrar a observação de Hodgson (2011, p. 22) de que "As instituiçôes dependem dos pensamentos e das atividades dos indivíduos, mas não podem ser reduzidas a eles", de forma que tal preocupação é relevante. Além disso, as iniciativas pessoais têm uma escala de penetração muito pequena na sociedade, como detalha esse entrevistado: “[...] não ficar só na iniciativa individual de um ou de outro pesquisador, ser algo mais institucional para também captar mais recursos, enfim, ter um pouco mais de volume de apresentação para sociedade, de retorno [...]" (GP30).

FIGURA 1

Dimensão individual

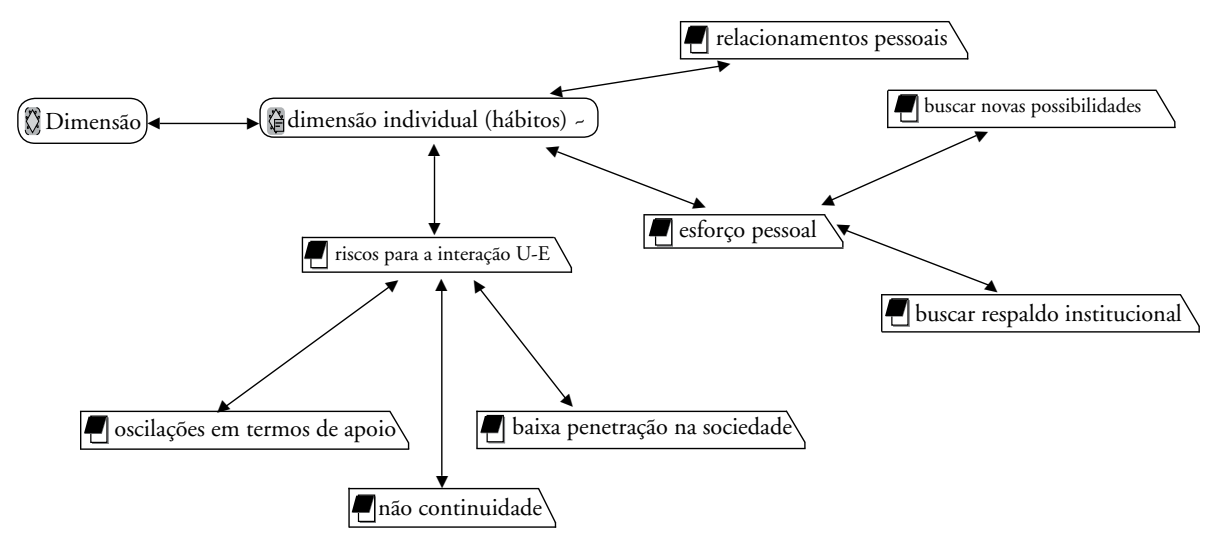

Fonte: Pesquisa de campo, 2013 
Para uma compreensão ampla da dimensão individual, a Figura 1 sintetiza os pontos centrais da análise que são os relacionamentos pessoais e o esforço pessoal, associados aos riscos para a interação U-E. A identificação da dimensão individual é importante, pois são os indivíduos que antecedem as organizações, argumento que ganha ainda mais força num ambiente organizacional em que tais indivíduos gozam de ampla autonomia e liberdade de escolha em seus comportamentos, como é o caso das universidades (TARTARI; BRESCHI, 2012).

\subsection{Dimensão coletiva}

$\mathrm{Na}$ análise da dimensão coletiva procurou-se resgatar como ocorre a interação entre pessoas e instituições, bem como se colocam as regras e o aprendizado envolvido neste processo. Também se investigou, na direção abordada por Hodgson (2011), de que forma o pensamento individual se torna ordenado, dando forma e consistência às atividades humanas.

O papel que a instituição assume ou a força do elemento institucional nas relações com o setor produtivo é, ao mesmo tempo, autorreforçante, na medida em que os entrevistados sinalizaram sua importância, e conflitante, quando determinadas regras colocadas pela institucionalização são questionadas ou quando conflitos são gerados a partir delas. Nesse sentido, em linha com North (1990), verifica-se que a instituição é capaz de reduzir a incerteza, o que a torna importante; mas, por outro lado, tal característica não garante sua eficiência, o que gera o conflito.

Com relação ao primeiro caso, os relatos que se seguem ilustram a importância das instituições atribuída pelos entrevistados: "Porque sem instituição não dá para fazer isso, impossível um pesquisador aqui, acontece se o pesquisador conhece alguém na empresa e tal, faz uma relação, mas é fraca” (GP10); “[...] as pessoas são fundamentais, mas esses mecanismos institucionais para auxiliar são importantes, porque senão trava [...] (GP30).

Hodgson (2011) amplia tal questão, afirmando que as instituições são dependentes das atividades dos indivíduos que as moldam, de forma que esse processo de retroalimentação conta com fortes características de autorreforçamento e autoperpetuação. Como as instituições dependem dos indivíduos para poder existir, suas interações e padrões de comportamento são fundamentais nesse sentido. Contudo, o indivíduo nasce em um mundo institucional preexistente, que o confronta com determinadas regras, podendo gerar o conflito. 
No que tange ao aspecto conflitante das instituiçōes, é preciso considerar o contexto no qual as relaçōes U-E se desenvolvem, bem como as mudanças recentes nesse campo em termos de regulação, o que faz com que as próprias estruturas internas da universidade ainda estejam se acomodando a partir do estabelecimento de determinadas regras, conforme ilustra essa colocação: "A institucionalização ela faz com que as coisas aconteçam de maneira organizada, embora não é garantia de que funcione bem. Tem certas coisas que funcionam, outras não funcionam" (GP10).

Um ponto importante assinalado por Hodgson (2011) em relação a esse aspecto é que a existência de regras implica restriçōes. Nesse sentido, os entrevistados apontam a dificuldade de lidar com essas restriçōes, que, se não forem entendidas adequadamente, acabam por resultar em conflitos. Contudo, o autor complementa que tais restriçôes podem justamente abrir possibilidades e ainda promover opções e ações que de outra maneira não existiriam, o que traz uma conotação positiva à situação.

Julgou-se também importante analisar o papel das instituições e sua evolução dentro de uma perspectiva histórica, considerando o caráter "path dependent" das mudanças. Assim, foi possível perceber que algumas dificuldades encontradas em termos de institucionalização têm raízes no passado, como complementa esse pesquisador: "tudo no Brasil é complicado, nós estamos ainda sendo colonizados, é tudo por fazer, não temos história nessa área e a história é toda conturbada e não termina, não fecha um ciclo de começo, meio e fim" (GP10).

Dentro da visão de North $(1990 ; 1991)$, segundo a qual as instituições podem assumir a perspectiva de restriçôes informais, ou regras formais, a pesquisa identificou aspectos em ambas as conotações. Com relação às restrições informais, encontram-se principalmente aspectos culturais, sobretudo contrários à interação U-E, conforme indica esse entrevistado: "Então a visão está muito ideologizada, e a ideologia é de que a universidade é pública e ela não pode estar associada ao sistema produtivo, industrial. Isso é um equívoco" (GP15),

Já as regras formais estão fortemente ancoradas no marco regulatório e isso ainda é um processo de transição, com estágios de maturidade diferentes em cada uma das universidades. Com relação a este fato, é preciso considerar que, para se converterem em regras, as novas leis têm que ser impostas até o ponto em que a falta ou a realização da conduta em questão se converta em um costume e assuma o status normativo (HODGSON, 2011).

As regras que dão forma às instituições estão diretamente relacionadas a um processo constante de transformação e, por conseguinte, de aprendizado, não no sentido estrito, considerando apenas a aquisição de conhecimentos na área de atuação, 
mas sim numa perspectiva ampla, levando em conta o ganho de experiência com o processo de interação em si. Uma das facetas da institucionalização é percebida pelos pesquisadores como a necessidade de maior profissionalização da universidade em seus formatos de interação com o setor produtivo, o que na visão deles está fortemente relacionado a aspectos de divulgação externa.

Um aspecto a ser ressaltado nessa direção é a representatividade das universidades pesquisadas nas iniciativas institucionais, como são os casos da UFSC, Udesc e Univali, que fazem parte do Conselho Municipal de Inovação de Florianópolis como membros representantes das instituiçôes de ensino superior, tecnológico e profissionalizante de Florianópolis. Iniciativa similar têm a Furb e Univali junto à Câmara de Inovação e Tecnologia da Acafe. Essas inserções são relevantes para fortalecimento das instituições e particularmente suas açôes no campo da inovação, uma vez que mantêm as universidades engajadas nas políticas governamentais e nas demandas da sociedade.

A Figura 2 destaca os pontos centrais da dimensão coletiva, que são o papel da instituição, a profissionalização, a perspectiva histórica e as regras. Com relação a este último aspecto, atenta-se para o fato de que as regras formais estão intimamente ligadas ao marco regulatório que inclui a Lei da Inovação no Brasil, ao passo que as restrições informais refletem os aspectos culturais que viabilizam ou dificultam as interações U-E.

\section{FIGURA 2}

Dimensão coletiva

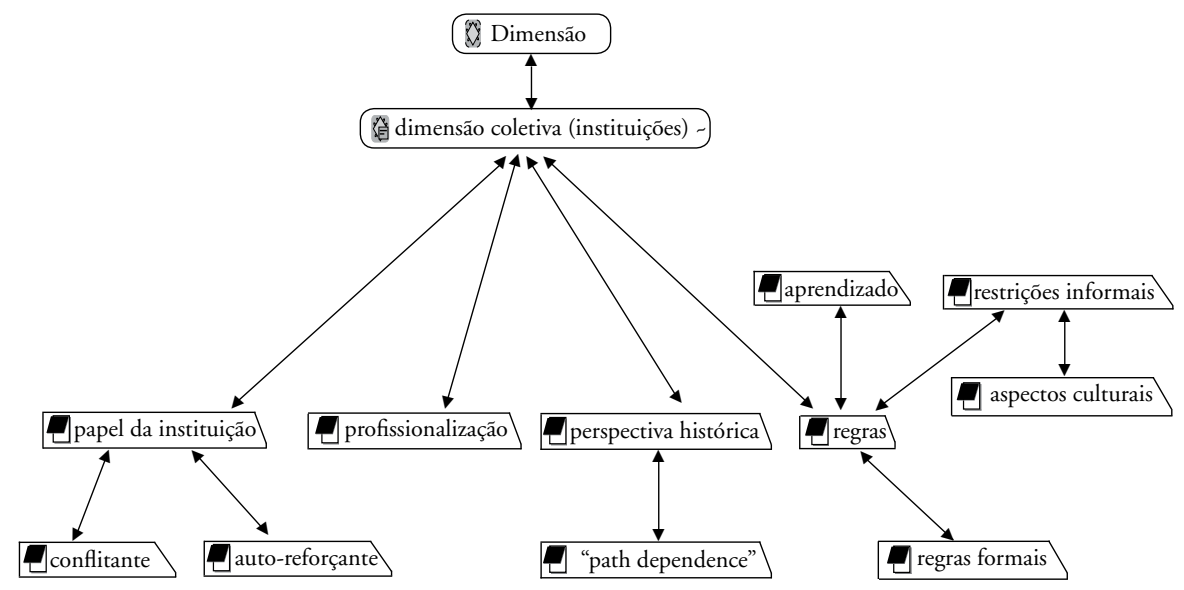

Fonte: Pesquisa de campo, 2013 
$\mathrm{Na}$ questão das regras formais, há ainda que se considerar a necessidade de conciliação da Lei de Inovação Brasileira às iniciativas estadual e municipal, o que acrescenta complexidade à regulamentação das parcerias entre universidades e empresas. Tal fato tem implicaçōes relevantes, principalmente, na Furb, cuja natureza é municipal e, portanto, depende da Lei de Inovação de Blumenau, que ainda encontra-se em discussão no município, e também na Udesc, de natureza estadual que está sujeita à Lei de Inovação Catarinense.

\subsection{Tecnologias físicas}

Nas tecnologias físicas, puderam-se observar, principalmente, os aspectos relacionados à infraestrutura física, incluindo os laboratórios e equipamentos utilizados, bem como os instrumentos adotados para a consolidação e formalização dos projetos desenvolvidos em colaboração com empresas. Sobre o ambiente físico de trabalho, constatou-se que mais de $70 \%$ dos grupos de pesquisa estão solidificados neste aspecto, sobretudo aqueles cuja interação com empresas já acontece há mais de cinco anos. Aqui também é possível resgatar a questão de que a infraestrutura física permite o compartilhamento de instalaçôes, que é utilizado tanto para criar um ambiente de trabalho colaborativo quanto para a realização de consultoria e pesquisa conjunta.

No tocante à questão dos equipamentos, os pesquisadores reforçam que muitos laboratórios foram montados graças ao financiamento externo, destacando o valor dos equipamentos e as possibilidades que eles trazem para o grupo em termos de avanços nas pesquisas que são desenvolvidas, como se pode ver no relato seguinte: "nós temos uma capacitação laboratorial muito boa em equipamentos, têm milhões e milhões de dólares em equipamento e assim, como foi feito isso? Através da empresa no início e depois através do grupo e tudo isso se torna para a universidade um benefício" (GP14).

Em relação aos instrumentos adotados para formalização e consolidação das parcerias, basicamente os entrevistados mencionaram os convênios e contratos, em que fica expressa uma forte atuação das Fundações de Apoio ligadas às universidades, notadamente no gerenciamento desses mecanismos. Sobre esse aspecto, verificam-se situaçóes particulares em cada uma das universidades. Na UFSC foi implantado o convênio tripartite, que envolve a anuência das três partes: UFSC, fundação e empresa. A Furb buscou identificar o papel de cada um dos atores da interação, no caso universidade, empresa e fundação, em sua política de inovação. Já na Udesc essa questão aparece como uma crítica ao fato de a universidade não utilizar a fundação da mesma forma como a UFSC. Na Univali esse aspecto não foi mencionado. De 
modo geral, o que se verifica é uma desorientação em relação ao papel desses atores no processo que não está muito claro dentro do marco regulatório de inovação.

Percebeu-se que existem diferentes graus de maturidade e envolvimento entre os pesquisadores, em relação à compreensão e aplicação de tais instrumentos, como se pode verificar nessa afirmação: "Embora eu não entenda da área, não sei nem te dizer a diferença entre um convênio e um contrato, [...] uso o modelo que o NIT recomenda desde então" (GP7). Também foi possível constatar que há forte ligação dos pesquisadores com os NITs da universidade, em função do aspecto jurídico envolvido e também pelo fato de que, normalmente, os NITs já têm modelos desses instrumentos definidos para as várias situaçôes de parceria previstas.

É importante destacar as visóes convergentes entre pesquisadores e gestores do NIT que acreditam na importância desses instrumentos e, sobretudo, na questão da proteção do conhecimento. O pesquisador e o gestor do NIT expressam-se utilizando praticamente as mesmas palavras para referir-se ao momento anterior à criação do NIT: " era uma terra de ninguém, a universidade não era defendida, digamos assim” (GP9); "Eu acho que era uma terra sem lei” (NIT1).

Verificou-se que, mesmo em se tratando de instrumentos para formalização das parcerias, é importante que se considerem os aspectos informais existentes, quer sejam o relacionamento pessoal, a proximidade com as empresas, a cultura, a história anterior e outros, pois eles invariavelmente interferem no processo. Como afirma North (1990), a esfera informal está sempre presente nas instituiçōes formais e, segundo Hodgson (2011), em qualquer contrato existem regras e normas que não necessariamente estão codificadas, o que acontece inclusive por razōes de praticidade e complexidade.

\section{FIGURA 3}

Tecnologias físicas

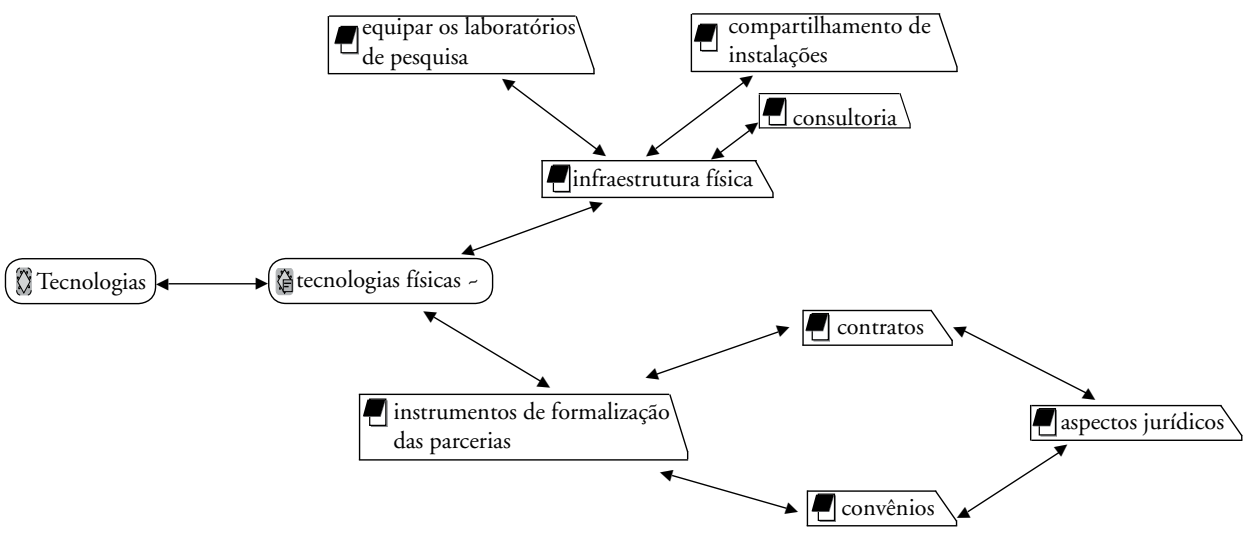

Fonte: Pesquisa de campo, 2013 
A Figura 3 reforça que os dois principais elementos das tecnologias físicas são a infraestrutura física e os instrumentos de formalização das parcerias. Nestes últimos verificam-se basicamente os contratos e convênios e sua ligação com os aspectos jurídicos. Já a infraestrutura física está relacionada aos equipamentos, às instalações e à realização de consultoria.

\subsection{Tecnologias sociais}

Nas tecnologias sociais, procurou-se identificar como funciona a organização interna dos grupos de pesquisa e, nesse decurso, como o trabalho é dividido entre os pesquisadores, de que maneira acontece a interface com as empresas envolvidas e quais as formas de comunicação comumente utilizadas nesse processo. Além disso, também foram apurados elementos acerca das estruturas de coordenação e direção.

Normalmente os grupos organizam-se de forma que seja possível a troca de experiências e competências entre os pesquisadores. A organização dos grupos de pesquisa também envolve elementos de planejamento, acompanhamento e controle do trabalho que está sendo desenvolvido, bem como a realização de reuniões periódicas e a elaboração de relatórios para entrega de resultados, como se pode ver: "Todos os projetos têm que ter o que, por que, como e quando. Tem um cronograma acertado junto com a empresa e como vai ser feita cada uma dessas coisas. A gestão, nós temos relatórios de avaliaçóes mensais, por exemplo, onde você vai avançando no cronograma e vai prestando contas" (GP12).

Especificamente para a parte de acompanhamento e controle, destaca-se o uso de metodologias específicas ou a utilização de sistemas que permitam identificar a qualquer momento o status dos projetos, conforme atesta o entrevistado: "Toda essa sistemática ela funciona com cronogramas, com controle [...] nós temos toda essa métrica de projeto que é temporal, desse acompanhamento de projeto e além dele temos os cronogramas e todos os alunos têm um sistema de controle interno" (GP17).

Neste aspecto da organização dos grupos de pesquisa, há uma aderência às características da noção de rotina associada ao conceito de tecnologia social (NELSON; SAMPAT, 2001), no sentido em que se percebe a atuação dos pesquisadores em criar caminhos para aquilo que deve ser feito, de forma clara, respeitando uma lógica de trabalho e permitindo que novos membros, ao ingressarem no grupo, compreendam e incorporem tais rotinas.

A respeito da divisão do trabalho entre os pesquisadores, verificou-se que ela acontece basicamente de duas formas: de acordo com as competências dos pesquisadores em suas áreas de conhecimento; e de acordo com o grau de conhecimento ou titulação que 
cada pesquisador possui. No primeiro caso, é comum que a alocação de atividades se dê em função das afinidades e experiências de pesquisa dos membros do grupo, conforme se percebe nessa colocação: "Depende da demanda que tem, e em função da demanda que tem você elenca os profissionais que estão relacionados com aquela demanda, pode ser que envolve todo o grupo como às vezes não, só envolve um ou dois" (GP23).

Há casos, no entanto, em que competências complementares ao grupo de pesquisa são necessárias, especialmente quando os projetos envolvem a aplicação de conhecimentos que não estão abrangidos dentro das linhas de pesquisa ou áreas de atuação do grupo. Nessas situações, são buscadas competências em outros grupos e áreas do conhecimento, formando parcerias entre pesquisadores.

Verificou-se que existem áreas do conhecimento em que as universidades têm destaque, o que se reflete no segmento produtivo nos setores de atividade que se relacionam com essas áreas. A questão geográfica pode se mostrar importante, como revela o caso da Furb com o setor de energia elétrica em Blumenau, mas não é determinante, como também ilustra o caso da Udesc em Joinville com o setor de eletroeletrônicos.

A divisão do trabalho por grau de conhecimento ou titulação acaba sendo natural por existirem nos grupos de pesquisa, além dos professores que normalmente assumem a posição de coordenação, alunos de graduação e pós-graduação, no nível de mestrado, doutorado e até pós-doutorado, que trabalham em seus projetos específicos, mas em colaboração com projetos mais amplos.

Outro aspecto observado sobre a divisão do trabalho entre os pesquisadores é que os grupos procuram também atender às demandas acadêmicas, ajustando as demandas do setor produtivo a trabalhos de conclusão de curso de graduação, dissertaçôes de mestrado e teses de doutorado. Nesse aspecto, existe uma preocupação com a formação dos alunos e a qualidade dos trabalhos desenvolvidos, conforme expressa esse relato: "Nós temos o cuidado de sempre, e isso é uma orientação forte nossa, de colocar o nosso pessoal de mestrado e doutorado e de graduação, então nós inserimos o fomento da pesquisa ao nosso graduando também dessa maneira, nós os colocamos em projetos externos" (GP 12).

A divisão do trabalho também envolve uma interface com as empresas, na medida em que existem uma atividade colaborativa e o envolvimento de técnicos ou pesquisadores provenientes do setor produtivo. Nesse aspecto, ganham importância as formas de comunicação utilizadas para estabelecimento de um fluxo de troca de conhecimentos que seja contínuo.

Tratando agora sobre as estruturas de coordenação e direção, verificou-se que este elemento apresenta-se tanto dentro do grupo de pesquisa em si, como na universidade como um todo, considerando seus níveis mais estratégicos. No nível do grupo de pesquisa, 
a coordenação encontra-se centrada na figura do professor líder do grupo, compartilhada muitas vezes com outros professores. Nesse processo de coordenação, pode-se resgatar o papel das sistemáticas de acompanhamento e controle, tratadas anteriormente na organização dos grupos de pesquisa, nos mais variados formatos, de acordo com o que se pode ver na sequência: "nós temos um sistema de gestão, com as atividades dos alunos mestrandos, doutorandos, onde está definido quem vai fazer as atividades" (GP27).

Complementando os resultados, Morandi (2013) acrescenta que as práticas de planejamento e controle são combinadas de diferentes formas, de maneira a gerir as atividades em cooperação. Nesse sentido, são as características do projeto e do tipo de relacionamento que determinam a configuração do sistema de gestão. Cada uma das fases do processo de interação envolve desafios de gestão específicos e até ferramentas especializadas, em alguns casos.

Ainda na questão da coordenação e direção, foi possível observar o papel atribuído à gestão da universidade, na figura de sua equipe diretiva, no que diz respeito à sua responsabilidade pela institucionalização das questôes ligadas à inovação e por consequência aos projetos desenvolvidos em parceria com o setor produtivo. Predomina o sentimento de que é papel da gestão alavancar possibilidades nessa direção, conforme manifesta esse entrevistado: "Nós precisamos que qualquer que seja a administração que ela tenha um olhar para o futuro do ponto de vista mais avançado, institucionalmente falando" (GP8).

\section{FIGURA 4}

Tecnologias sociais

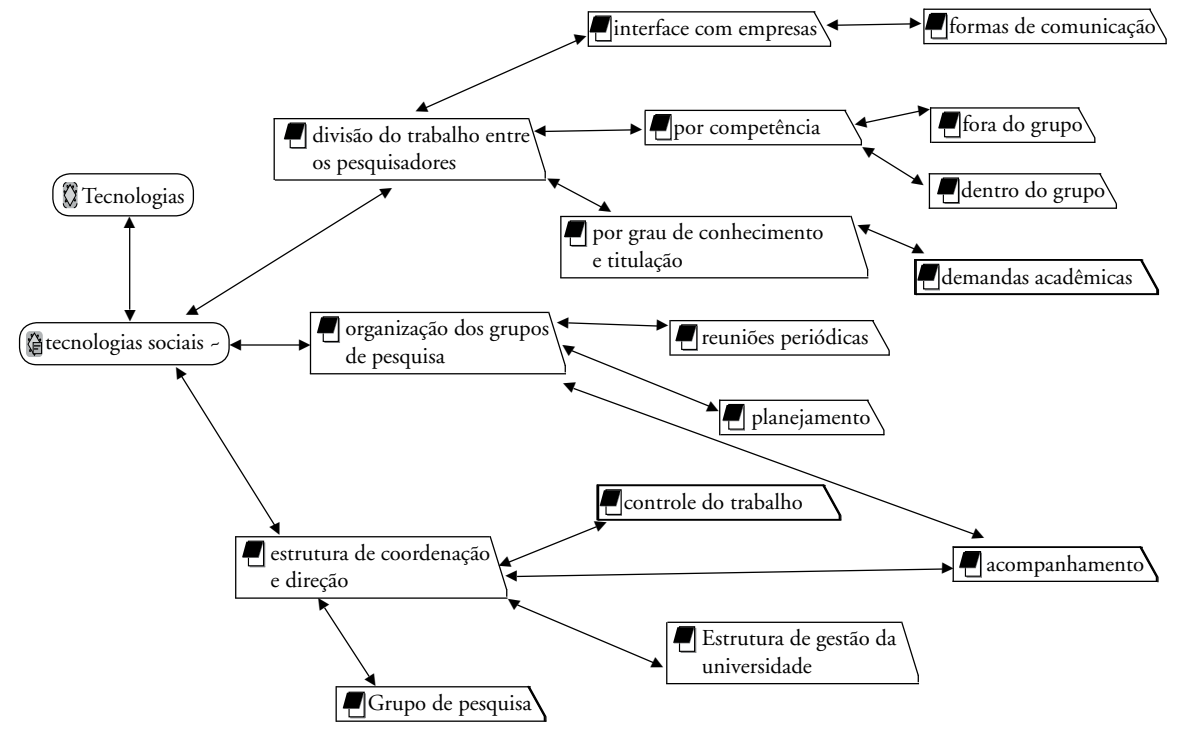

Fonte: Pesquisa de campo, 2013 
Em consonância, apresenta-se a Figura 4, que enfatiza os três pontos principais das tecnologias sociais e suas decorrências: a organização dos grupos de pesquisa; a divisão do trabalho entre os pesquisadores; e as estruturas de coordenação e direção. Destaque é dado para as questôes de acompanhamento e controle de trabalho que estão presentes tanto na organização dos grupos de pesquisa como nas estruturas de coordenação e direção.

\section{Considerações finais}

A análise da dimensão individual e coletiva revelou-se importante para este estudo por permitir identificar tanto o caráter pessoal como institucional das açóes, verificando que são basicamente os comportamentos individuais que definem os relacionamentos com as empresas e que são esses comportamentos que se tornam institucionalizados ou não no decorrer desse processo, transformando-se numa expressão coletiva. Nessa direção, tomaram-se como verdade as proposiçōes de Hodgson (2011) embasadas no fato de que indivíduos e estruturas institucionais são diferentes, mas permanecem frequentemente interconectados.

Verificou-se que a dimensão individual, pelas evidências apresentadas, mostra-se relevante dentro do processo de interação U-E, uma vez que os relacionamentos pessoais e o esforço individual de cada pesquisador são aspectos determinantes para o início e a continuidade dos projetos em parceria. Há o reconhecimento explícito de que a ênfase no aspecto pessoal traz riscos e que a passagem para a dimensão coletiva nem sempre é simples, pois as instituições podem ao mesmo tempo reduzir incertezas e gerar conflitos. As regras formais existentes tentam criar certa estabilidade de atuação, mas, por se encontrarem ainda em processo de formação e serem influenciadas pelas restrições informais, não conseguem desempenhar esse papel por completo. Tudo isso gera um processo de aprendizado permanente que mantém a dinâmica institucional em funcionamento.

Para aprofundar a análise da dinâmica institucional, além da dimensão individual e coletiva a pesquisa, buscou-se respaldo no conceito de tecnologia física e tecnologia social proposto por Nelson e Sampat (2001) e Nelson (2006, 2008). Nesse sentido, foi possível investigar os principais instrumentos empregados nas universidades no que se refere às interaçóes com empresas, bem como verificar os formatos de organização, divisão e coordenação do trabalho. Tal enfoque contribuiu para revelar detalhes da forma de organização das atividades que dizem respeito ao processo de interação U-E. 
De maneira geral, contatou-se que os mecanismos institucionais, apesar de contribuírem para a intensificação dos relacionamentos U-E, não são suficientes para garantir o sucesso dessas relaçôes que dependem também de fatores associados ao seu próprio amadurecimento. O estágio de evolução das interações U-E, na maior parte dos casos, é ainda bastante embrionário, assim como a própria trajetória dos grupos de pesquisa dentro das universidades. Há que se ressaltar, no que diz respeito ao ano de formação, que a maior parte dos grupos (20 deles) foi criada nos anos 2000, sete foram formados na década de 1990, três na década de 1980 e ainda um grupo nos anos 1970, o que revela uma trajetória de pesquisa ainda recente.

Da mesma forma, a estrutura institucional que sustenta o processo também se encontra em plena situação de desenvolvimento, sofre com a pouca experiência acumulada e precisa mobilizar um complexo conjunto de requerimentos num contexto de mudanças tecnológicas, culturais e institucionais. Os casos de sucesso identificados, cujas parcerias estão consolidadas e ocorrem de forma contínua, têm origem nos grupos de pesquisa com maior tempo de existência, ou seja, dois grupos criados na década de 1980 e um nos anos 1990.

Concluiu-se, portanto, que o processo de interação U-E em Santa Catarina encontra-se bastante condicionado à dimensão individual, de maneira que muitos comportamentos ainda não se institucionalizaram a ponto de produzir vínculos fortes, relações duradouras e resultados consistentes. Nesse sentido, percebe-se que a aproximação com o setor produtivo e o estabelecimento de parcerias não se configuram de fato como uma estratégia institucional, mas refletem ações isoladas de pesquisadores, grupos de pesquisa ou departamentos. Outra evidência nessa direção é a própria estrutura dos NITs que as universidades apresentam, comparativamente menos estratégicos e com menos recursos em relação a outras estruturas internas.

\section{Referências bibliográficas}

BERNARDES, A.; ALBUQUERQUE, E. M. Cross-over, thresholds and the interactions between science and technology: lessons for less-developed countries. Research Policy, v. 2, n. 5, p. 867-887, 2003.

BEKKERS, R.; FREITAS, I. M. B. Analysing knowledge transfer channels between universities and industry: to what degree do sectors also matter? Research Policy, v. 37, p. 1837-1853, 2008.

BOARDMAN, P. C. Government centrality to university-industry interactions: university research centers and the industry involvement of academic researchers. Research Policy, v. 38, p. 1505-1516, 2009. 
CAPES. GEOCAPES: Dados estatísticos. 2012. Disponível em: <http://geocapes.capes.gov. br/geocapesds/>. Acesso em: 31 out. 2013.

CNPq - Conselho Nacional de Desenvolvimento Científico e Tecnológico. Diretório dos Grupos de Pesquisa do CNPq. Censos 2002 a 2010. S/d. Disponível em: <http://dgp.cnpq. br/censos/index.htm>. Acesso em: 22 jun. 2013.

COHEN, W. M.; NELSON, R. R.; WALSH, J. P. Links and impacts: the influence of public research on industrial R\&D. Management Science, v. 48, n. 1, p. 1-23, jan. 2002.

CONCEIÇÃO, O. A. C. Tecnologia social e instituiçôes: uma relação conceitual simbiótica. Economia \& Tecnologia, ano 5, v. 16, p. 99-108, jan./mar. 2009.

. Há compatibilidade entre a "tecnologia social" de Nelson e a "causalidade vebleniana” de Hodgson? Revista de Economia Política, v. 32, n. 1, p. 109-127, jan./mar. 2012.

DAGNINO, R. Tecnologia social: ferramenta para construir outra sociedade. Campinas- SP: Komedi, 2010.

Research Policy, v. 37, p. 1-11, 2008.

. What makes an economy productive and progressive? What are the needed institutions? Pisa, Italy: Laboratory of Economics and Management, Sant'Anna School of Advanced Studies, 2006 (Working paper, 24).

NELSON, R. R.; NELSON, K. Technology, institutions, and innovation systems. Research Policy, v. 31, p. 265-272, 2002.

NELSON, R. R.; SAMPAT, B. Making sense of institutions as a factor shaping economic performance. Journal of Economic Behavior \& Organization, v. 44, p. 31-54, 2001.

NORTH, D. C. Institutions, institutional change and economic performance. Cambridge: Cambridge University Press, 1990.

. Institutions. Journal of Economics Perspectives, v. 5, n. 1, p. 97-112, winter, 1991.

PAVITT, K. Innovation processes. In: FAGERBERG, J.; MOWERY, D. C.; NELSON, R. R. The Oxford handbook of innovation. New York: Oxford University Press, 2007, p. 86-114. PEREIRA, A. J.; DATHEIN, R. Processo de aprendizado, acumulação de conhecimento e sistemas de inovação: a "co-evolução das tecnologiasfísicas e sociais" como fonte de desenvolvimento econômico. Revista Brasileira de Inovação, v. 11, n. 1, p. 137-166, jan./jun. 2012. PERKMANN, M.; KING, Z.; PAVELIN, S. Engaging excellence? Effects of faculty quality on university engagement with industry. Research Policy, v. 40, p. 539-552, 2011.

SAAD, M; ZAWDIE, G. Introduction to special issue: the emerging role of universities in socio-economic development through knowledge networking. Science and Public Policy, v. 38 n. 1, p. 3-6, Feb. 2011.

TARTARI, V.; BRESCHI, S. Set them free: scientists' evaluations of the benefits and costs of university-industry research collaboration. Industrial and Corporate Change, v. 21, n. 5, p.1117-1147, 2012. 